\title{
Pequeno panegírico para José de Anchieta, o cenógrafo
}

Short panegyric to José de Anchieta, the scenographer

\section{Fausto Viana}

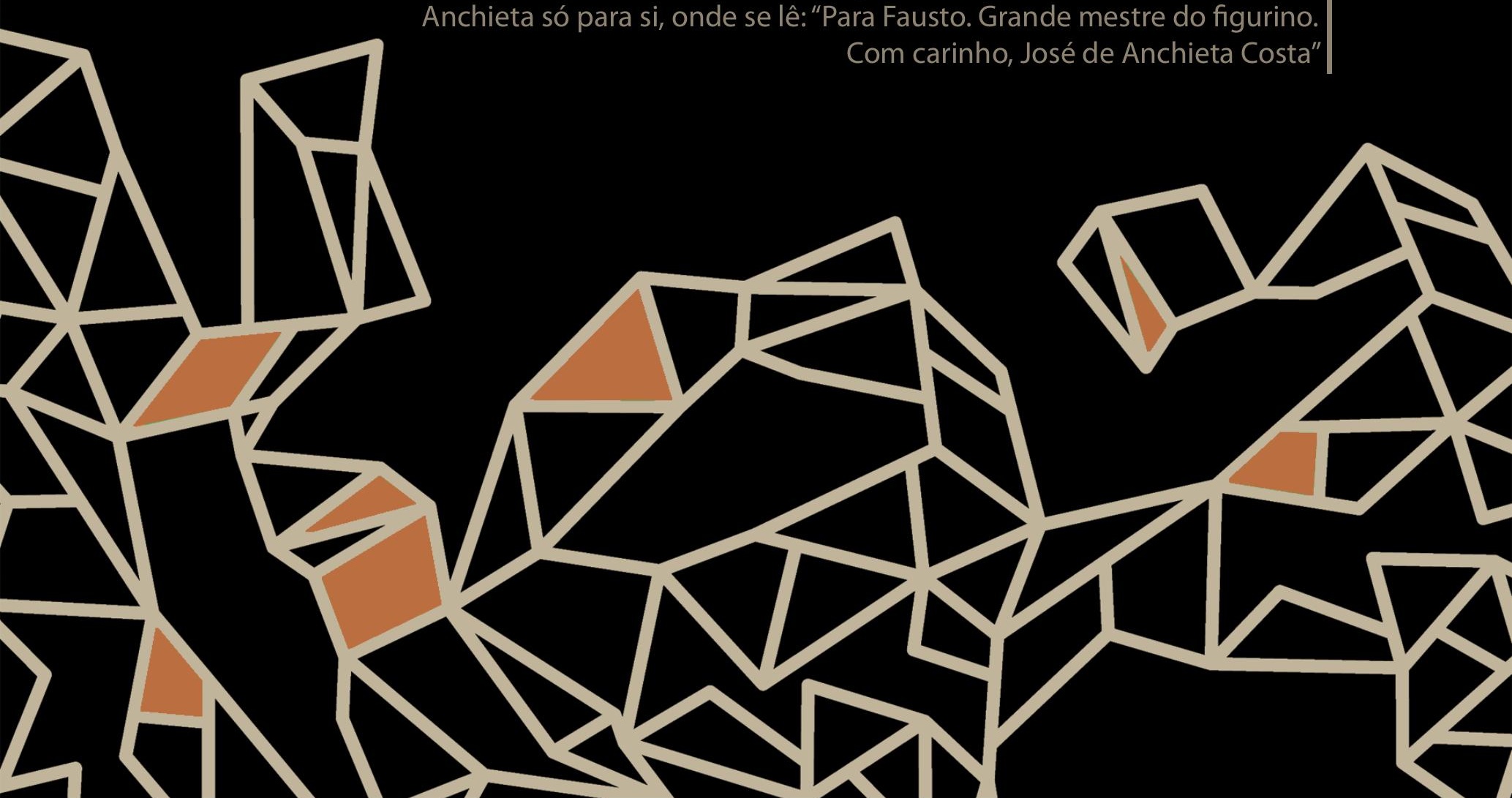

Fausto Viana

Fausto Viana é pesquisador de trajes de cena e professor de Cenografia

e Indumentária na Escola de Comunicações e Artes da Universidade de São Paulo. É doutor em Artes e em Museologia e fez pós-doutorado em Conservação de Trajes e Moda. É autor do livro O figurino teatral e as renovações cênicas do século XX e $O$ traje de cena como documento, entre outros. E se gaba de ter o livro Cenograficamente com uma assinatura do Anchieta só para si, onde se lê: "Para Fausto. Grande mestre do figurino.

Com carinho, José de Anchieta Costa" 
O teatro prescinde do sono, do descaso e da preguiça;

Quem os tiver que procure outro ofício. Nós temos

toda a morte para dormir!

José de Anchieta (2002, p. 233)

Dias se passaram desde a morte do cenógrafo José de Anchieta em 23 de maio de 2019, aos 71 anos, de complicações ligadas ao diabetes, quando me foi solicitado este texto sobre ele. Inicialmente, me soou como um necrológio, algo fúnebre e pesado que senti não ter absolutamente nenhuma compatibilidade com a vida incrível de José de Anchieta Costa, um homem divertido, culto, trabalhador e artista nascido em Caruaru, Pernambuco, em 23 de fevereiro de 1948. Fui pesquisar - e como ele era bom em fazer pesquisas! - e descobri a palavra encômio no Houaiss eletrônico (INSTITUTO ANTÔNIO HOUAISS, 2009, n.p.): "fala ou discurso em louvor de alguém; elogio, e também, na Grécia antiga, hino religioso de louvor". Eu me animei, era o caminho. Joguei no dicionário de Raphael Bluteau, de 1728, que explicou o seguinte (em adaptação livre):

Deriva-se do grego en\&Comi, como quem dissera em latim Invico, porque entre os gregos Encômio era propriamente um louvor público, que se dava na rua, na praça etc.; segundo Scaligero, Encômio vale o mesmo que $\mathrm{Pe}$ queno paneg írico, quando o louvor não é tão breve, que acabe logo, mas quando tem alguma extensão e ornato de palavras.(BLUTEAU, 1728, p. 91)

Achei uma graça no contexto porque o José de Anchieta - que nasceu na fazenda Fulorina, que era de seu avô - foi para um seminário aos 10 anos, em 1958, e lá estudou grego e latim. O avô o havia predestinado a servir à Igreja, sugerindo o nome do apóstolo do Brasil para o recém-nascido. "Fui para o seminário com a promessa de que lá havia uma grande piscina, com a qual sempre sonhei” (ANCHIETA, 2015, p. 58). No seminário, entre muitas atividades, fez teatro, "acho que ocorreu o meu deslumbramento e encantamento com os costumes e o figurino" (Ibid., p. 69), a partir da observação dos trajes sacerdotais. "O teatro entrou no meu sangue como a salvação de uma doença incurável: a rebeldia" (lbid., p. 72), ele disse. Para nossa sorte, a Igreja percebeu sua falta de talento para a vida apostólica e o expulsou em 11 de junho de 1962. No mesmo ano, estreou como ator na TV Cultura, em diversos programas liderados por Lúcia Lambertini, e também como ator de teatro em Nossa cidade, com direção de Eduardo Curado. 
Não parou nunca mais.

No Teatro Popular do Sesi, entre 1963 e 1964, trabalhou como ator e cenógrafo. No Teatro de Arena, fez várias produções como ator, cenógrafo e figurinista, entre 1965 e 1967.

Em 1969, foi contratado para trabalhar em uma produtora de comerciais para a TV - era necessário ganhar dinheiro. "Durante mais de vinte anos, trabalhei em publicidade paralelamente à minha atividade teatral, até mesmo pela questão óbvia da sobrevivência financeira" (ANCHIETA, 2002, p. 228). Ainda em 1969, produz um filme de curta-metragem em que assina direção, roteiro, cenografia e figurino.

Cenografia é toda a parte visível do universo. E a invisível também. José de Anchieta (2002, p. 26)

Em 1970, produziu com Roberto Santos o filme Um anjo mau, longa-metragem em que assina a cenografia e o figurino. A partir de 1976, esteve pontualmente na TV Globo, empresa para a qual faria diversos trabalhos, e foi responsável, entre outras, pela cenografia de Estúpido cupido. Teve passagens também na TV Tupi, TV Bandeirantes e TV Manchete.

Trabalhou com grandes nomes do teatro brasileiro: Silnei Siqueira, Antunes Filho, Ademar Guerra, Kiko Jaess, Jonas Bloch, Antônio Abujamra, Cecil Thiré, Gracindo Júnior, Flávio Rangel, Sérgio Britto, Bibi Ferreira, Gianfrancesco Guarnieri, lacov Hillel, e muitos outros. E Cacá Rosset.

O desenvolvimento de cenografia e figurinos com Cacá Rosset talvez tenha sido o de maior projeção para Anchieta, em uma parceria muito produtiva que começou em 1989, com O doente imaginário, de Molière (Figura 1). "A estreia nacional foi em Sertãozinho, no interior de São Paulo, e de lá partimos para Nova York, onde estreamos na sala Newman do The Public Theater, de Joseph Papp" (ANCHIETA, 2015, p. 300). Cacá Rosset já vinha agitando o fazer teatral. Em 1990, produziram Sonho de uma noite de verão, adaptação que ficou famosa pelos minúsculos tapa-sexos usados pelas atrizes que interpretavam as fadas. Em 1992, estrearam A comédia dos erros. Em 1998, O avarento, de Molière (ver o desenho do cenário na Figura 2). Em 2000, Scapino, também de Molière. Em 2006, O marido vai à caça, de Georges Feydeau. Em 2008, A megera domada. 


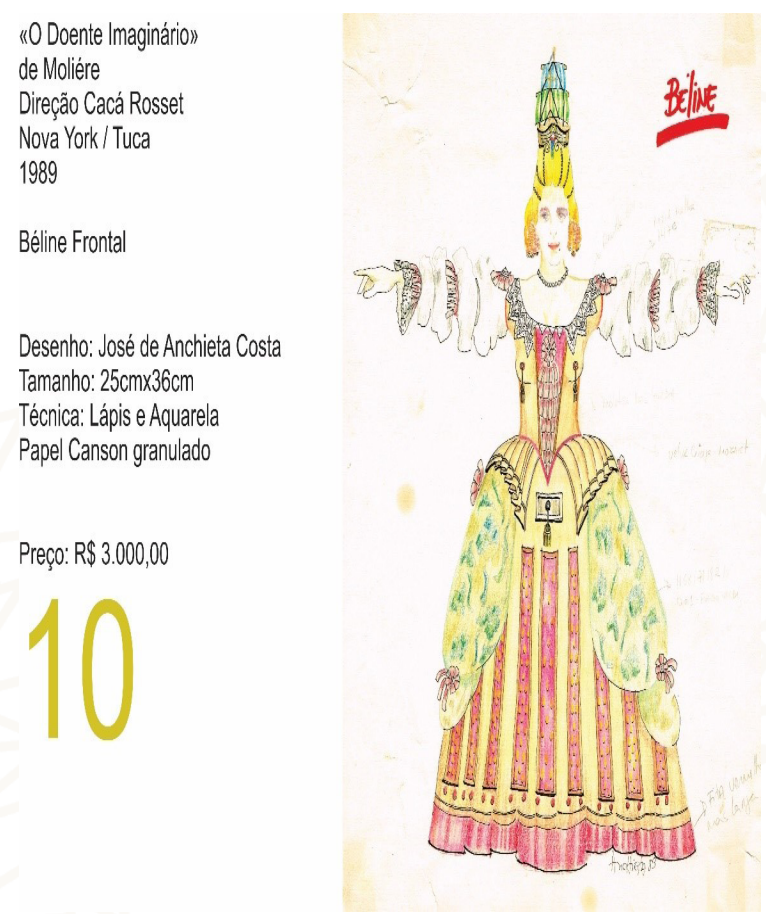

Figura 1 - Desenho de traje de cena para a personagem Beline, interpretada pela atriz Christiane Tricerri, em O doente imaginário (1989)

Fonte: Acervo do autor

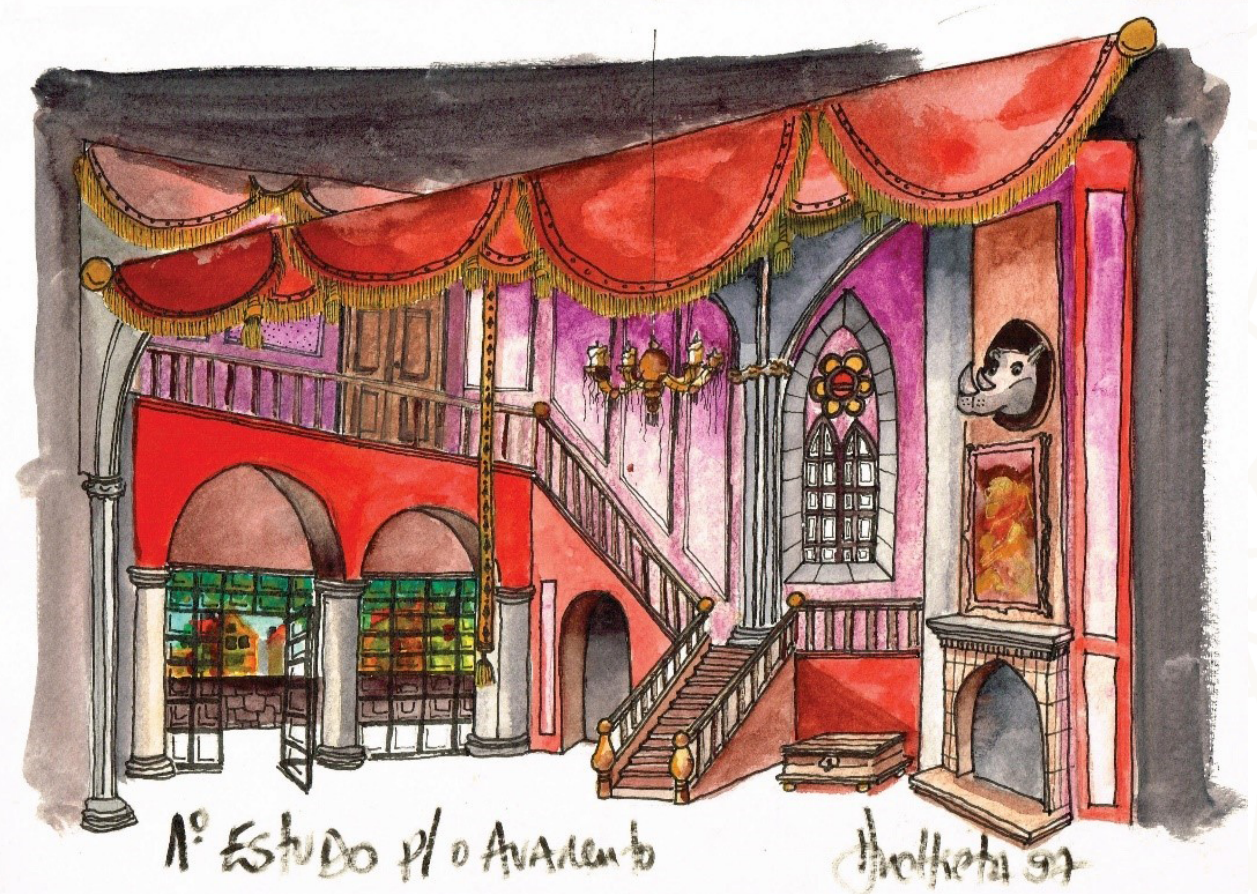

Figura 2 - Estudo para o cenário de O avarento (1998), de Molière. Direção de Cacá Rosset

Fonte: Acervo do autor 
Os prêmios foram muitos. APCA, Prêmio Padre Anchieta, Governador do Estado, Kikito, Mambembe, Coca-Cola de Teatro... Na Quadrienal de Praga de 1995, foi premiado juntamente com Daniela Thomas e J. C. Serroni, recebendo do júri a seguinte avaliação:

Protocolo final do júri da Quadrienal Internacional de Praga de 1995: O júri outorgou a Golden Triga de 1995 para o Brasil, que dilata a atmosfera festiva do fenômeno teatral e o visualiza como um lugar de prazer e excitação. Os designers brasileiros criam seu trabalho para peças que acontecem em espaços encontrados, bem como em palcos tradicionais, abrindo as portas para novas formas e ousando encontros teatrais. (ANCHIETA, 2002, p. 21)

O ano de 2019 foi também o de seu último trabalho de cenografia e figurinos. No Theatro Municipal de São Paulo, com direção de Cleber Papa, ele fez $O$ barbeiro de Sevilha, de Gioachino Rossini ${ }^{1}$.

Anchieta escreveu também dois livros Auleum: a quarta parede, de 2002, e Cenograficamente, de 2015 e com o qual pude contribuir com um capítulo falando sobre o trabalho dele. O segundo deve esgotar-se rapidamente; portanto, corra.

Que bela trajetória. José de Anchieta disse - e acho que não haveria melhor modo de encerrar o nosso pequeno panegírico - que a maior lição da vida dele, ele aprendeu com Cacá Rosset: "rir é o melhor remédio, a solução para todos os males. Trabalhamos por prazer e não para sofrer... E como tem gente que gosta de sofrer!" (ANCHIETA, 2015, p. 306).

\section{Referências bibliográficas}

ANCHIETA, J. Auleum: a quarta parede. São Paulo: Abooks, 2002.

ANCHIETA, J. Cenograficamente: da cenografia ao figurino. São Paulo: Edições Sesc, 2015.

BLUTEAU, R. Vocabulario portuguez e latino aulico, anatomico, architectonico, bellico, botanico, brasilico, comico, critico, chimico, dogmatico, dialectico, dendrologico, ecclesiastico, etymologico, economico, florifero, forense,

1 O leitor pode acessar esta que talvez seja a última gravação de José de Anchieta falando sobre seu trabalho, no seguinte link: https://bit.ly/2yYwOl4. Acesso em: 16 jul. 2019. 
fructifero... autorizado com exemplos dos melhores escritores portugueses,

e latinos. Coimbra: Collegio das Artes da Companhia de Jesus, 1728. 1 v.

INSTITUTO ANTÔNIO HOUAISS. Houaiss eletrônico. São Paulo: Objetiva, 2009.

1 CD-ROM.

Recebido em 18/07/2019

Aprovado em 18/07/2019

Publicado em 30/08/2019 